\title{
La intimidad como derecho humano y la solidaridad como valor constitucional en la era del Covid-19
}

\author{
Privacy as a human right and \\ solidarity as a constitutional \\ value in the era of Covid-19
}

\author{
DOI: https://doi.org/10.17981/juridcuc.17.1.2021.10
}

Fecha de Recepción: 2020/11/10 Fecha de Aceptación: 2021/01/05

Felix Ramon Mendoza de la Espriella

Corporación Universitaria del Caribe-CECAR. Sincelejo (Colombia) felix.mendoza@cecar.edu.co

\author{
Abraham Zamir Bechara Llanos \\ Corporación Universitaria del Caribe-CECAR. Sincelejo (Colombia) \\ abraham.becharall@cecar.edu.co \\ Joe Caballero Hernández \\ Corporación Universitaria del Caribe-CECAR. Sincelejo (Colombia) \\ joe.caballeroh@cecar.edu.co
}

Para citar este artículo:

Mendoza, F., Bechara, A. \& Caballero, J. (2021). La intimidad como derecho humano y la solidaridad como valor constitucional en la era del Covid-19. Jurídicas CUC, 17(1), 277-298. DOI: http://dx.doi. org/10.17981/juridcuc.17.1.2021.10

\section{Resumen}

El objetivo de este artículo de investigación es abordar desde una perspectiva analítica los alcances del derecho humano a la intimidad, y la afectación al valor de la solidaridad. A partir de medidas estatales con ocasión a la emergencia del COVID-19, como fenómeno de salud pública con implicaciones jurídicas, haciendo especial relación al sistema juridico colombiano. Para este cometido trabajaremos dos tópicos fundamentales: (i) El derecho a la intimidad en Colombia: garantias bajo los márgenes conceptuales de la corte constitucional. (ii) El valor de la solidaridad a examen: constitucionalidad del decreto 568 de 15 de abril del 2020. En este orden como conclusiones preliminares, evidenciamos que la constitucionalidad de la intimidad y la solidaridad, pueden ser puestas en peligro a partir de las lesiones a las garantias primarias como normas axiológicas, que se encuentran bajo la tutela y titularidad de protección del poder ejecutivo central, frente a la declaratoria del Estado de emergencia económica, social y ecológica, que consagra el artículo 215 de nuestra Ley Fundamental.

Palabras clave: Intimidad; derechos humanos; solidaridad; covid-19

\begin{abstract}
The objective of this research article is to approach from an analytical perspective the scope of the human right to privacy, and the impact on the value of solidarity. Based on state measures on the occasion of the emergency of COVID-19, as a public health phenomenon with legal implications, making special relation to the Colombian legal system. For this purpose we will work on two fundamental topics: (i) The right to privacy in Colombia: guarantees under the conceptual margins of the constitutional court. (ii) The value of solidarity under examination: constitutionality of decree 568 of April 15, 2020. In this order as preliminary conclusions, we show that the constitutionality of privacy and solidarity can be endangered from the damage to the guarantees primary as axiological norms, which are under the guardianship and protective ownership of the central executive power, against the declaration of the State of economic, social and ecological emergency, enshrined in article 215 of our Basic Law.
\end{abstract}

Keywords: Privacy; human rights; solidarity; covid19

(C) The author; licensee Universidad de la Costa - CUC. 


\section{INTRODUCCIÓN}

El derecho que ostenta toda persona a poseer y disfrutar de su ámbito propio y a su protección de cara a la injerencia ilegal de terceros se entiende como el derecho a la intimidad. Este atributo de protección constitucional y por los tratados internacionales de derechos humanos, forma parte del bloque de constitucionalidad, tiene como componentes el buen nombre, la honra, las comunicaciones, el domicilio, su pasado, las relaciones con los demás, a no ser fotografiado, o registradas sus llamadas o a la anotación de su actividad en ambientes electrónicos, a no ser sujeto de filmación o registro magnetofónico alguno, a que no se conozcan ni se den a conocer sus hábitos, menos aún a que cualquier labor propia se divulgue, su espacio y relaciones laborales o familiares, origen racial o étnico, la orientación política, las convicciones religiosas o filosóficas, la pertenencia a sindicatos, organizaciones sociales, de derechos humanos o que promueva intereses de cualquier partido político o que garanticen los derechos y garantías de partidos políticos de oposición, así como los datos relativos a la salud, a la vida sexual, los datos biométricos, y todos aquellos aspectos que son del ámbito privado y que los reserva para sí mismo.

La protección al derecho a la intimidad es coincidente en la Constitución Política (CP, 1991), los instrumentos internacionales de protección de los derechos humanos, la ley, la jurisprudencia y la doctrina nacional e internacional. El derecho a la intimidad es un derecho de todo ser humano y su ejercicio debe garantizarse de manera plena.

La incursión sin antecedentes en la vida diaria de las personas y, en especial, los desarrollos electrónicos, han posibilitado que la informática acceda hasta lo más oculto de esa cotidianeidad, a un derecho de antigua data como lo es el derecho a la intimidad, recupera especial significación y emerge con una innovadora complejidad en su protección. De esta manera lo admite Calle (2009), al sostener que, en relación con el derecho a la intimidad, la expansión de las sociedades ha comportado su mutación, transitando del determinismo individual a la autodeterminación informativa, como efecto 
del fenómeno tele-informático que va irrumpiendo en todas las esferas de la vida moderna (Cobos, 2013).

Así, la tecnología y su empleo a redes de comunicación cada vez más evolucionadas, conlleva la necesidad de examinar y regular la tendencia creciente de bases de datos de información individual. La información personal no se recoge indiscriminadamente, sino en determinados sectores estratégicos de la sociedad, como son la educación, la salud, la estructura financiera, la correspondencia y el sistema judicial, amén de otras áreas.

La contestación que un buen número de estados ha proporcionado ante esa emergente carencia de preceptiva del derecho a la intimidad, se localiza en la normativa denominada de protección de datos de carácter personal y, es de considerar que, a su amparo, el derecho a la intimidad adquiere una trascendencia sin antecedentes cuyo primordial dispositivo de amparo está fundado en el habeas data, pero aclarando que no es este elemento el único que la intimidad preserva. Y esto es cierto, ya que en el tiempo en que Warren y Brandeis (1890) dieron a conocer su renombrado artículo «The Rigth to Privacy", no alcanzaban ni lejanamente concebir el avance que los medios de comunicación llegarían a tener en la era moderna. Para los autores este derecho se enfila en torno a la injerencia de los medios que ya en 1890 causaban molestias en el ámbito personal de los ciudadanos. Ahora bien, es indudable los riesgos para los derechos humanos que comporta el uso de aplicaciones de búsqueda de la Covid-19, que implica la puesta en marcha de programas de localización móvil que los gobiernos implementan en la tarea de defensa de la salud pública.

\section{Desarrollo}

MetodoloGía

En este orden inicial, realizaremos un ejercicio de concreción normativa en nuestro segundo acápite y final, donde analizaremos conceptual y pragmáticamente la solidaridad como valor constitucional; donde expresaremos nuestras consideraciones, argumentos de razones y 
elementos interpretativos, por los que la Corte Constitucional ponderó, una decisión justa y enmarcada en los límites estructurales, de la teoría estándar de los derechos fundamentales y de la Constitución, en el control judicial que emana del artículo 215 Constitucional, en el marco del Estado de emergencia económica, social y ecológica por el Covi-19 en Colombia, a partir de la declaratoria de inconstitucionalidad del "decreto de impuesto solidario" (Decreto 568, 2020).

\section{Discusión}

El derecho a la intimidad en Colombia: garantias bajo los márgenes conceptuales de la corte constitucional

Para explicar el derecho a la intimidad en el territorio colombiano, es importante remitirnos a la Constitución Política de Colombia (CP, 1991), la cual regula todos los aspectos políticos, jurídicos, militares, económicos, sociales, y otros de las relaciones humanas en toda la nación colombiana, como en efecto lo contempla en su artículo 15, el derecho a la intimidad.

Sin embargo, el contenido histórico, filosófico y jurídico que encontramos en el trasfondo de esta carta política nos revela la argumentación que va a ser desarrollada por el principal órgano judicial, el cual, determina como debemos entender o interpretar el derecho a la intimidad, este órgano es la Corte Constitucional colombiana.

En primera medida, el Estado colombiano es un Estado Social de Derecho, el cual es una evolución del Estado Liberal burgués que comprende como uno de sus derechos principales el derecho a la libertad. Las revoluciones liberales de finales del siglo XVIII derrocaron el Estado Monárquico en las revoluciones norteamericana y francesa, posteriormente las latinoamericanas, con el propósito de garantizar la libertad individual en todos los ciudadanos pertenecientes al Estado de Derecho. En efecto, el Estado deja de ser impositivo y permite el desarrollo individual de todas las personas, en sentido civilista, con la consigna dejar hacer dejar pasar. Solo funge como ente de control de las acciones penales o violatorios de los bienes jurídicos tutelados. 
En este contexto, el derecho a la intimidad o al desarrollo individual, es clave, y va muy ligado al derecho a la libertad. De hecho, después de la Segunda Guerra mundial los estados occidentales que participaron, todos de tendencia liberal, redactan la Declaración Universal de Derechos Humanos (Organización de las Naciones Unidas-ONU, 1948), en la cual, exponen todos los derechos de gran importancia para la civilización occidental. En el artículo 12 de la misma se redacta el derecho a la intimidad de la siguiente manera:

Nadie será objeto de injerencias arbitrarias en su vida privada, su familia su domicilio o su correspondencia, ni de ataques a su honra o a su reputación. Toda persona tiene derecho a la protección de la ley contra tales injerencias o ataques (ONU, 1948, art. 12).

No obstante, todos los demás Estados contemplaron esta declaración y los derechos estipulados como base para las futuras constituciones. Así, con la evolución del Estado de Derecho Liberal Burgués a Estado social y constitucional de Derecho en la Constitución de Bonn, (Ley Fundamental de la República Federal de Alemania, 1949), todos estos derechos fueron contemplados, incluyendo el derecho a la intimidad. Superando las anquilosadas tensiones conceptuales y pragmáticas provenientes de los sistemas jurídicos de tradición legalista. Así, como "los resultados de los intereses contrapuestos tengan rasgos de cumplir no solo con el principio de legalidad fundante de la noción de Estado de derecho de tradición decimonónico, sino de una observancia real del principio de justicia" (Carrillo y Bechara, 2019b, p. 233).

En la ONU, también se ratificaron los derechos expuestos en la Declaración de los Derechos Humanos (ONU, 1948) mediante el Pacto Internacional de Derechos Civiles y Políticos (ONU, 1966), donde se establece que:

Nadie será objeto de injerencias arbitrarias o ilegales en su vida privada, su familia, su domicilio o su correspondencia, ni de ataques ilegales a su honra y reputación. Toda persona tiene derecho a la protección de ley contra esas injerencias o esos ataques (art. 17.1). 
En Latinoamérica, fue ratificado con la Convención Americana sobre Derechos Humanos (Organización de Estados AmericanosOEA, 1969), que también creo una Corte Interamericana de Justicia para garantizar esos derechos, en donde reza:

Nadie puede ser objeto de injerencias arbitrarias o abusivas en su vida privada, en la de su familia, en su domicilio o en su correspondencia, no de ataques ilegales a su honra o reputación. Toda persona tiene derecho a la protección de la ley contra esas injerencias o esos ataques (art. 11.2).

Por tanto, el derecho internacional les brinda estos referentes jurídicos a todos los estados para que puedan aplicarlo de forma práctica en las sociedades liberales occidentales. Esta protección se inició en el caso de la actriz Brigitte Bardot (1959), en donde los Tribunales norteamericanos decidieron que el hecho de que una persona fotografiara a otra en su residencia y publicara tales fotografías sin ningún tipo de autorización, a pesar de la manifestación inequívoca de refugiarse en su casa, violaba la intimidad de la demandante.

Este es el primer referente judicial sobre la protección al derecho a la intimidad. Después de este, posteriormente siguieron varios casos importantes para proteger este derecho. sin embargo, dada la importancia en la protección de este derecho mediante una argumentación jurídica, el tribunal norteamericano desarrollo la doctrina the rigth to be let alone, es decir, el derecho a ser dejado solo, aplicado en este caso con el objeto garantizar la libertad de la demandante mediante el derecho a la intimidad sin ninguna restricción (Sentencia C-881, 2014).

Otro referente judicial importante, es la Sentencia del caso Tristán Donoso vs. Panamá, en la Corte Interamericana de Derechos Humanos (CIDH, 2009b), la cual estudio la interceptación, grabación y divulgación de una conversación telefónica de un abogado y la posterior apertura de un proceso penal por delitos contra el honor como represalia a las denuncias del señor Tristán Donoso sobre la referida grabación y divulgación. En esta sentencia se señaló que: 
El derecho a la vida privada no es un derecho absoluto y, por lo tanto, puede ser restringido por los estados siempre que las injerencias no sean abusivas o arbitrarias; por ello, las mismas deben estar previstas en ley, perseguir un fin legítimo y cumplir con los requisitos de idoneidad, necesidad y proporcionalidad, es decir, deben ser necesarias en una sociedad democrática (Tristán Donoso vs. Panamá, 2009b).

Es decir, puede existir una violación al derecho a la intimidad, pero con un fin legítimo. Considerando, que este es el primer referente judicial que limita el derecho a la intimidad en Latinoamérica.

Otro caso importante, es el desarrollado en la sentencia del Caso Escher y Otros vs. Brasil, también de la Corte Interamericana de Derechos Humanos (CIDH, 2009a). Esta resolución judicial analizó la legitimidad de las medidas de interceptación y monitoreo de comunicaciones realizada a unos ciudadanos. En ella se señalaron una serie de criterios respecto de la injerencia en la intimidad de las personas, las cuales considera que son las siguientes:

a) Estar prevista en ley; b) perseguir un fin legítimo, y c) ser idónea, necesaria y proporcional (Escher y Otros vs. Brasil, 2009a).

El Tribunal Europeo de Derechos Humanos asimismo ha desarrollado el concepto de Reasonable Expectation of Privacy, en español es traducido como expectativa razonable de intimidad. Este concepto fue utilizado por primera vez en el caso Halford vs United Kingdom (1997), para indicar que las interceptaciones realizadas a los teléfonos del trabajo de una empleada de la policía con la finalidad de discriminarla y obstaculizar su ascenso vulneraron el derecho a la intimidad de la empleada, por lo cual, se le brindo protección a su derecho.

Este concepto, desde entonces, ha sido adaptado en el sistema acusatorio o sistema de derecho penal en varios países occidentales como doctrina limite en la garantía del derecho a la intimidad, precisamente por las actuaciones de investigaciones penales por parte de la policía judicial. 
En Colombia, ha sido reiterativa la Corte Constitucional con un concepto similar a los referentes internacionales mencionados. Este concepto, de derecho a la intimidad, ha sido explicado en múltiples sentencias desde la entrada en vigor de la Constitución (1991), el cual reza lo siguiente:

El derecho a la intimidad hace parte de la esfera o espacio de vida privada no susceptible de la interferencia arbitraria de las demás personas, que al ser considerado un elemento esencial del ser, se concreta en el derecho a poder actuar libremente en la mencionada esfera o núcleo, en ejercicio de la libertad personal y familiar, sin más limitaciones que los derechos de los demás y el ordenamiento jurídico (Sentencia T-517, 1998; Sentencia C-692, 2003; Sentencia C-872, 2003; Sentencia T-787, 2004, Sentencia C-336, 2007).

Es decir, el derecho a la intimidad es la facultad de exigir de los demás el respeto de un ámbito exclusivo del individuo, el respeto de sus posesiones privadas, de sus propios gustos y de aquellas acciones muy personales que no está dispuesto a exhibirle a los demás. Este derecho no contempla las intromisiones exteriores de otros individuos a menos a que sea permitido (Sentencia T-552, 1997).

Por lo tanto, para explicar desde su propia doctrina el aspecto teórico de este derecho, la misma Corte Constitucional ha contemplado dos dimensiones trascendentales. La primera, es el derecho a la intimidad como secreto que impide la divulgación ilegítima de hechos o documentos privados. La segunda, es el derecho a la intimidad como libertad, explicado en este escrito, que se realiza en el derecho de toda persona a tomar las decisiones que conciernen a la esfera de su vida privada, sin que nadie más interfiera en las mismas. Ahora bien, el artículo 15 (CP, 1991) amplia el concepto con la vinculación de la familia, las informaciones sobre la persona, la correspondencia y demás formas de comunicación privada.

Por lo tanto, el derecho a la intimidad plantea diferentes esferas o ámbitos, como son: 1) el Personal, 2) el Familiar, 3) el Social y 4) el Gremial. Todos ellos comprendidos en el artículo 15 (CP, 1991), y que concretamente en la práctica podemos identificarlos: 
a. En las relaciones familiares.

b. En las costumbres tanto personales como con otros individuos.

c. En las prácticas sexuales.

d. En la salud y la psicológica como producto de patologías.

e. En su domicilio, entendido por la Corte como todos aquellos espacios cerrados en donde las personas desarrollan su intimidad, no necesariamente se refiere a su casa de habitación.

f. En sus comunicaciones personales.

g. En espacios para la utilización de datos a nivel informático, con todo el mercado de las redes sociales.

h. En las creencias religiosas con los secretos confesionales y demás.

i. En los secretos profesionales de sus agremiaciones laborales.

En general, en todo comportamiento del sujeto que únicamente puede llegar al conocimiento de otros, siempre y cuando el mismo individuo decida relevar autónomamente su acceso al público (Sentencia SU-089, 1995).

Desde el punto de vista espacial la Corte distingue tres tipos de lugares con niveles de protección distintos respecto del derecho a la intimidad. Dependiendo del lugar, se permitirá una mayor o menor injerencia por parte de particulares o autoridades del Estado. Estos lugares son:

1. El espacio público, reconocido en la CP (1991), que establece como deber del Estado "velar por la protección de la integridad del espacio público y por su destinación al uso común, el cual prevalece sobre el interés particular" (art. 82). El espacio público es en este contexto un derecho ciudadano de acceso, utilización y goce, como también, un lugar en el que se ejercen múltiples derechos, en un contexto mediado por normas y susceptible de ser restringido por las autoridades, por lo cual el derecho a la intimidad podrá limitarse en el mismo (Sentencia C-881, 2014).

2. El espacio privado se define como el lugar donde la persona desarrolla libremente su intimidad y su personalidad en un "ámbito reservado e inalienable" (Sentencia C-881, 2014). En este sentido, las residencias y los lugares en los que las personas habitan son 
el espacio privado por excelencia. Empero, la jurisprudencia ha admitido que el desarrollo de la intimidad y el libre ejercicio de las libertades individuales, también se produce en el domicilio, que "comprende, además de los lugares de habitación, trabajo, estudio, todos aquellos espacios o recintos aislados en los que la persona normal y legítimamente pretenda desarrollar su propia vida privada, separada de los terceros y sin su presencia" (Sentencia C-881, 2014). Al igual que el espacio público, el espacio privado, es tanto un derecho como un lugar en el que se ejercen derechos, principalmente la intimidad y las libertades individuales. Así, la garantía y protección de los espacios privados, está estrechamente asociada a la noción de intimidad y por ello la limitación de este derecho en los mismos debe ser excepcional (Sentencia C-881, 2014).

3. Existe también el espacio semi-privado o espacio semi-público. En un extremo se encuentra la calle como espacio público por excelencia y, de otro lado, el domicilio privado como espacio privado por definición. Espacios "intermedios" que tienen características tanto privadas como públicas, son los lugares de trabajo como las oficinas, los centros educativos como los colegios y las universidades, los restaurantes, los bancos y entidades privadas o estatales con acceso al público, los almacenes y centros comerciales, los cines y teatros, los estadios, los juzgados y tribunales, entre otros (Sentencia C-881, 2014).

Las limitaciones del derecho a la intimidad, según la Corte Constitucional, pueden darse por dos (2) razones:

1. Cuando el interés general se ve comprometido y se perjudica la convivencia pacífica o se amenaza el orden justo, cierta información individual puede y debe ser divulgada. Intereses de orden superior justifican la limitación del derecho a la intimidad para efectos tributarios, judiciales y de inspección, vigilancia e intervención del Estado.

2. En determinadas circunstancias, cuando se presente una colisión con otros derechos individuales que compartan el carácter de fundamental como, por ejemplo, el derecho a la información, la dignidad humana y la libertad. 
Es importante resaltar lo estipulado por la CP (1991, art. 15), donde detalla que solo mediante orden judicial, en los casos y con las formalidades establecidas por ley para limitar este derecho.

Por otra parte, además de la conexión existente del derecho a la intimidad con el derecho a la libertad, también es posible asegurar que existe una conexión con el derecho al buen nombre, tal como lo resalta la CP (1991, art. 15). De hecho, la Corte Constitucional lo ha conceptualizado de la siguiente manera:

El derecho al buen nombre tiene carácter personalísimo, relacionado como está con la valía que los miembros de una sociedad tengan sobre alguien, siendo la reputación o fama de la persona el componente que activa la protección del derecho. Se relaciona con la existencia de un mérito, una buena imagen, un reconocimiento social o una conducta irreprochable, que aquilatan el buen nombre a proteger, derecho que es vulnerado cuando se difunde información falsa o inexacta, o que se tiene derecho a mantener en reserva, con la intención de causar desdoro contra el prestigio público de una persona (Sentencia T-949, 2011).

Por otra parte, también tiene una conexión ideológica con el derecho a la honra (CP, 1991, art. 21), el cual, la Corte ha conceptualizado de la siguiente manera:

Ha sido asociado por la jurisprudencia constitucional a la valoración de comportamientos en ámbitos privados. Esta Corte ha dicho que la honra hace referencia a "la estimación o deferencia con la que, en razón a su dignidad humana, cada persona debe ser tenida por los demás miembros de la colectividad que le conocen y le tratan", y protege el valor intrínseco de los individuos frente a la sociedad y frente a sí mismos, garantizando la adecuada consideración y valoración de las personas dentro de la colectividad, por lo que se deriva de la propia dignidad de la persona. En el mismo sentido, en la Sentencia T-322 de 1996 se indicó que el núcleo esencial del derecho a la honra lo integran tanto la perspectiva interna, esto es, la estimación que cada persona hace de sí misma, y la perspectiva externa, que consiste en el reconocimiento que los demás hacen de la dignidad de cada individuo. Además, precisó que para que pueda tenerse como afectado este derecho, esos dos factores deben apreciarse de manera conjunta (Sentencia T-411, 1995). 
El valor de la solidaridad a examen:

Constitucionalidad del Decreto 568 del 15 de abril de 2020

Recientemente la Honorable Corte Constitucional declaró la inexequilibidad del llamado impuesto solidario, consagrado en el Decreto 568 (2020), en este acápite final presentaremos los argumentos, por los cuales la decisión de la Corte es acertada, desde el análisis de la teoría de los valores, la dogmática constitucional, la jurisprudencia de principios (Bechara, 2017) y la teoría y praxis de los derechos fundamentales que se ha venido construyendo en Colombia, a lo largo de 30 años de doctrina constitucional.

El decreto de la referencia; desvirtúa la jurisprudencia que la Corte, ha instituido en Colombia para la aplicación de la teoria de los valores ${ }^{1}$, y las normas estructuralmente consideradas como disposiciones tipo valor. Positivizadas constitucionalmente, por nuestra Constituyente en el Preámbulo, con verdadero valor normativo de nuestra Ley Fundamental (Guastini, 2010, p. 95).

En este orden conceptual, la teoria estándar de los derechos fundamentales, la cual concibe a los valores como normas axiológicas de lo bueno, según la concepción Alexyana (Alexy, 2007, p. 118), donde la actual Corte Constitucional ha investido como mandatos de optimización pretorianos (Sentencia T-195, 2019,) y como "jurisprudencia de principios" (Bechara, 2019, pp. 104-105) en una simbiosis normativa, entre valores y principios.

Los cuales, en términos de adjudicación de los derechos, al ser la solidaridad un bien colectivo, es instituida como norma valorativa, al encontrase en su relación de colisión con múltiples derechos fundamentales, y estos vistos como principios entrarían en una injerencia negativa."Los ciudadanos han de tomar conciencia en que la Constitución ha de justificarse en virtud de principios metajurídicos, es decir, principios cuya validez no puede depender de que el derecho positivo coincida con ella o no" (Portela, 2020, p. 279).

${ }^{1}$ La Corte Constitucional ha configurado la teoría de los valores, y los elementos procesales de la solidaridad como norma tipo valor en la Sentencia T-406 (1992), Sentencia C-1287 (2001) y Sentencia C-274 (2016). 
La injerencia en los círculos de múltiples derechos y bienes jurídicos fundamentales, ya protegidos con anterioridad, generan una expectativa normativa posterior, en una especie de ultraactividad infinita y remota. Como ejemplo, pensemos en la afectación al principio constitucional y derecho fundamental al mínimo vital y móvil, de funcionarios del Estado en gracia de pensión de jubilación.

Si bien la pandemia mundial, es un hecho imprevisto que no tendría por qué haberse conocido, ni mucho menos tenerse elementos preparatorios, para su eventual contención, no puede arrojar como respuesta a ello, la "expectativa negativa" de las decisiones del ejecutivo, y su ciudadanía en la recepción de estas. Generando "Cargas invertidas a sus derechos fundamentales" (Bechara, 2019, p. 111), la mayoría consagradas muchos lustros antes, e inclusive décadas a atrás, que generarían rupturas sistémicas a sus derechos. Resulta importante además, identificar la conceptualización de la solidaridad desde la teoría de los derechos humanos y el derecho internacional humanitario. Como lo definen Bermejo y Lamadrid (2020):

La solidaridad cobra vigencia en el espíritu de la mayoría, sobre todo en estos tiempos de crisis humanitaria que viven los países, desde la visión política, social, económica y cultural. Pero, sobre la cual, intervenidos los espacios de opresión y miseria humana, pudiera fundarse el reinado de la paz, siempre y cuando se asuma la conciencia democrática de los pueblos, y el establecimiento del estado de bienestar y del buen vivir de sus ciudadanos (p. 72).

El Decreto con pretensión de constitucionalidad, hasta su declaratoria a contrario sensu, el pasado miércoles 5 de agosto de 2020, el cual desconoció el parágrafo único del Artículo 215 Constitucional (CP, 1991) que signa los elementos interpretativos al ejecutivo central, a la hora de justificar una norma proveída, en términos de la declaratoria del Estado de emergencia económica y social, no puede desconocer la jurisprudencia del interprete autentico. Que no puede verse afectada so pretexto de una "agilidad de formulación 
normativa" en estos decretos que respetan la voluntad del gobierno nacional de Colombia, y las medidas que como verdaderas políticas públicas, configuran garantias a los derechos fundamentales, como reducción a las "injerencias negativas" (Jakobs, 2001, p. 13), que pueden traer cada una de ellas a los destinarios de las normas, expectativas representadas en la ciudadanía en general, y en particular en el grupo poblacional, sobre el cual el decreto se concretiza, esto es; funcionarios y servidores públicos del Estado.

El Decreto 568 (2020) presentó grandes falencias en los sustentos probatorios; de acuerdo con las estadísticas presentadas por el Departamento Administrativo Nacional de Estadística (DANE), respecto a la economía informal, ya que dicha encuesta fue realizada en enero del 2019, y solo se tuvo en cuenta dicha encuesta para colocar como sujeto pasivo es decir los que van a tener la facultad de adquirir dicho impuesto a los trabajadores de economía informal y a los trabajadores de clase media vulnerable.

Ahora bien; otro punto importante que no se sustentó probatoriamente y que carece tambien de fundamentos facticos y jurídicos; es el tópico de "la clase media vulnerable", pues presentan estadísticas que no son claras, que no tienen fecha de realización, por el principio mínimo de trasparencia de la función pública, rompe la "proporcionalidad media, que generara una falta de balanceo" (Carrillo y Bechara, 2019a, p. 64).

En sentido estricto de los derechos fundamentales afectados. Garantías laborales, todas afectadas a la dependencia del núcleo familiar de los destinatarios, en algunos casos puede lesionarse flagrantemente, en nivel elevado, un rango normativo del derecho fundamental, a la prevalencia del interés del menor, de la medida "impuesto solidario".

Esto se evidencia, en la carencia total de los fundamentos probatorios en una proporcionalidad como subprincipio de idoneidad, para aseverar que el $42.4 \%$ de los trabajadores en Colombia; trabajan por cuenta propia lo que hace que su situación laboral se vea gravemente afectada, por las medidas de política pública en salud, adoptadas para contener el Covid-19, nuevamente dejando sin peso concreto, el 
debate juridico solicitado para la creación de un impuesto solidario COVID-19 para los trabajadores de clase media y los trabajadores informales.

Al no ser claro el Gobierno Nacional con el mencionado decreto, respecto a la determinación expresa, de quienes son los trabajadores de clase media, en la que no se vislumbra a que grupo de colombianos, hace referencia cuando se dispone de un concepto ampliamente indeterminado y abiertamente discrecional, como es el concepto de trabajadores de clase media, encontrándonos aquí con un vacío normativo reglado; que no expone los sujetos pasivos que se favorecerán con este impuesto, elemento esencial de la teoria del derecho tributario rompiéndose flagrantemente el principio de legalidad del tributo (Sentencia C-117, 2018). expuesto constitucionalmente en la doctrina de la Corte Constitucional.

En el decreto, solo se tuvieron en cuenta los siguientes sujetos pasivos; (i).¿ servidores públicos de la rama ejecutiva, legislativa y judicial que devenguen 10.000.000 de pesos o más; del orden nacional, territorial etc, (ii) y los pensionados cuya mesada, sea de diez millones o más. Donde no se vislumbra, los elementos de inferencia lógica, interpretativa y los estándares argumentales de coherencia (Carrillo, 2018, p. 302) que tuvieron; para solo indicar a estos sujetos pasivos del tributo, dejando por fuera las personas naturales o jurídicas que tengan un salario de más de 10 millones de pesos, es decir teniendo en cuenta; que solo mencionan al sector público en cabeza de la rama de sus ramas ejecutiva, legislativa y judicial.

Por ultimo y no siendo menos importante; teniendo en cuenta que existen muchos más vacíos jurídicos en este decreto; es importante que al no darse la calidad conceptual mínima, el principio de seguridad juridica en sentido material se vulnera, en la forma de no establecer, la forma de garantizar la realización de las verificaciones, de la destinación de los dineros de los objetos contractuales, que se deriven del impuesto, específicamente a la Contraloría General de la República que tendría la responsabilidad de realizar estas revisiones y seguimiento fiscales. 


\section{Conclusiones}

La intimidad como derechos humano fundamental y la solidaridad como valor constitucional, se instituyen en la era de la COVID-19 como normas integrantes de nuestro marco político y normativo esencial. Las dos normas configuran un carácter axiológico que se nutre desde el intérprete atentico de la Constitución en Colombia, como se estructura a partir de las competencias del artículo 241. Superior.

La relación interpretativa se da aún más desde una perspectiva garantista, desde el parágrafo único del artículo 215 Constitucional (CP, 1991) que predica la declaratoria del Estado de emergencia, económico y social. Activando inmediatamente las competencias de la interpretación y el examen concreto de constitucionalidad, cuando el ejecutivo expedida el decreto que convoque no solamente el Estado de emergencia por la COVID19, sino además sus posteriores decretos. Lo que ha configurado en nuestra cultura jurídica lo que denominamos interpretación ejecutiva. Su protección debe predicarse en vía de las garantias tanto primarais como secundarias, en los márgenes estructurales de acción que ha desarrollado la Corte Constitucional, y la jurisprudencia Interamericana de derecho humanos, como especial control de convencionalidad.

Finalmente, ningún Estado y en especial el gobierno colombiano puede transgredir esta categoría especial de derechos, que generan una conexidad material polivalente, ya que configura dentro de la teoria estándar de los derechos fundamentales, proveniente de la Europa continental, la llamada garantía terciaria, que es aquella que se construye desde la jurisprudencia normativa de principio, por la necesidad de establecer un limite al ejecutivo desmedido en su actuar desproporcionando en el ejercicio de las garantias primarias o de primer nivel. 


\section{REFERENCIAS}

Alexy, R. (2007). Teoria de los derechos fundamentales. (2. Ed.). Madrid: Centro de Estudios Políticos y Constitucionales.

Bechara, A. (2019). Jurisprudencia de principios. Barranquilla/ Bogotá, D.C.: Universidad Externado de Colombia/Universidad del Norte.

Bechara, A. (2017). Jurisprudencia de principios e interpretación de la Constitución: el escenario de la Corte Constitucional colombiana. Justicia, 2(32), 15-37. https://doi.org/10.17081/ just.23.31.2903

Bermejo, J. y Lamadrid, J. (2020). Derechos humanitarios como prospectiva de los derechos humanos en Latinoamérica. Jurídicas CUC, 16(1). 69-96. http://dx.doi.org/10.17981/ juridcuc.16.1.2020.03

Calle, S. (2009). Apuntes Jurídicos sobre la protección de datos personales a la luz de la actual norma de Habeas Data en Colombia. Precedente. Revista Jurídica, 119-136. https:// doi.org/10.18046/prec.v0.1459

Carrillo, Y. (2018). Filosofia del Derecho. Bogotá, D.C.: Doctrina y Ley.

Carrillo, Y. y Bechara, A. (2019a). La Balanza de los derechos. Bogotá, D.C.: Grupo Editorial Ibáñez.

Carrillo, Y. y Bechara, A. (2019b). Juez discrecional y garantismo: Facultades de disposición del litigio en el código general del proceso. Jurídicas CUC, 15(1), 229-262. https://doi. org/10.17981/juridcuc.15.1.2019.09

Cobos, A. (2013). El contenido del derecho a la intimidad. Revista Mexicana de Derecho Constitucional, (29), 45-81. http:// dx.doi.org/10.1016/S1405-9193(13)71290-3

CIDH. (2009a). Escher y Otros vs. Brasil. [Online]. https://www. corteidh.or.cr/docs/casos/articulos/seriec_200_esp1.pdf 
CIDH. (2009b). Tristán Donoso vs. Panamá. [Online]. Recuperado de https://www.corteidh.or.cr/docs/casos/articulos/seriec_193_esp.pdf

European Court of Human Rights. (25 june 1997). (20605/92) [1997] ECHR 32. [Halford v. United Kingdom]. Disponible en http://www.hrcr.org/safrica/privacy/Halford.html

Guastini, R. (2010). Teoria e ideología de la interpretación constitucional. (2 ed.). Madrid: Trotta.

Jakobs, G. (2001). Injerencia y dominio del hecho. Bogotá, D.C.: Universidad Externado de Colombia.

OEA. (1969). Convención Americana Sobre Derechos Humanos. [Online]. Disponible en https://www.cidh.oas.org/basicos/ spanish/basicos2.htm

ONU. (1966). Pacto Internacional de Derechos Civiles y Políticos. [Online]. Disponible en https://www.ohchr.org/sp/professionalinterest/pages/ccpr.aspx

ONU. (1948). Declaración Universal de Derechos Humanos. [Onli$n e$ \}. Disponible en https://www.un.org/es/universal-declaration-human-rights/

Portela, J. (2020). El derecho en tiempos de crisis: una aproximación a las nociones de verdad y justicia. Jurídicas CUC, 16(1), 269-286. http://dx.doi.org/10.17981/juridcuc.16.1.2020.11

República de Colombia. Asamblea Nacional Constituyente. (1991). Constitución Política de Colombia 1991. Actualizada con los Actos Legislativos a 2016. [Online]. Recuperada de https://www.corteconstitucional.gov.co/inicio/Constitucion\%20politica\%20de\%20Colombia.pdf

República de Colombia. Corte Constitucional. (14 de mayo de 2019). Ref.: Expediente T-7.129.961. [Sentencia T-195]. M.P. Jose Fernando Reyes Cuartas. Disponible en https://www.corteconstitucional.gov.co/relatoria/2019/t-195-19.htm 
República de Colombia. Corte Constitucional. (14 de noviembre de 2018). Ref.: Expedientes D-12128. [Sentencia C-117]. M.S. Gloria Stella Ortiz Delgado. Disponible en https:// www.corteconstitucional.gov.co/relatoria/2018/C-117-18. htm

República de Colombia. Corte Constitucional. (25 de mayo de 2016). Ref.: Expediente D-11099. [Sentencia C-274]. M.P. Luis Ernesto Vargas Silva. Disponible en https://www. corteconstitucional.gov.co/RELATORIA/2016/C-274-16. htm

República de Colombia. Corte Constitucional. (19 de noviembre de 2014). Ref.: Expediente D-10273. [Sentencia C-881]. M.P. Jorge Ignacio Pretelt Chaljub. Disponible en https:// www.corteconstitucional.gov.co/relatoria/2014/C-881-14. htm

República de Colombia. Corte Constitucional. (16 de diciembre de 2011). Ref.: Expediente T-3176089. [Sentencia T-949]. M.P. Nilson Pinilla Pinilla. Disponible en https://www. corteconstitucional.gov.co/relatoria/2011/T-949-11.htm

República de Colombia. Corte Constitucional. (9 de mayo de 2007). Ref.: Expediente D-6473. [Sentencia C-336]. M.P. Jaime Córdoba Triviño. Disponible en https://www.corteconstitucional.gov.co/RELATORIA/2007/C-336-07.htm

República de Colombia. Corte Constitucional. (18 de agosto de 2004). Ref.: Expediente T-722765. [Sentencia T-787]. M.P. Rodrigo Escobar Gil. Disponible en https://www. corteconstitucional.gov.co/relatoria/2004/t-787-04.htm

República de Colombia. Corte Constitucional. (12 de agosto de 2003). Ref.: Expediente D-4424. [Sentencia C-692]. M.P. Marco Gerardo Monroy Cabra. Disponible en https:// www.corteconstitucional.gov.co/relatoria/2003/C-692-03. htm 
República de Colombia. Corte Constitucional. (30 de septiembre de 2003). Ref.: Expediente D-4537. [Sentencia C-872 ]. M.P. Clara Inés Vargas Hernández. Disponible en https:// www.corteconstitucional.gov.co/relatoria/2003/c-872-03. htm

República de Colombia. Corte Constitucional. (5 de diciembre de 2001). Ref.: Expediente D-3549. [Sentencia C-1287]. M.P. Marco Gerardo Monroy Cabra. Disponible en https://www. corteconstitucional.gov.co/relatoria/2001/C-1287-01.htm

República de Colombia. Corte Constitucional. (21 de septiembre de 1998). Ref.: Expediente T-166764. [Sentencia T-517]. M.P. Alejandro Martínez Caballero. Disponible en https:// www.corteconstitucional.gov.co/relatoria/1998/t-517-98. htm

República de Colombia. Corte Constitucional. (30 de octubre de 1997). Ref.: Expediente T-137.224. [Sentencia T-552]. M.P. Vladimiro Naranjo Mesa. Disponible en https:// www.corteconstitucional.gov.co/relatoria/1997/t-552-97. htm

República de Colombia. Corte Constitucional. (1 de marzo de 1995). Ref.: Proceso T- 41.500. [Sentencia No. SU-089]. M.P. Jorge Arango Mejia. Disponible en https://www.corteconstitucional.gov.co/relatoria/1995/ SU089-95.htm\#: :text=SU089\%2D95\%20Corte\%20 Constitucional\%20de\%20 Colombia\&text $=\mathrm{E} 1 \% 20$ conflicto $\% 20$ entre\% 20 el\%20derecho,por $\% 201 \mathrm{a} \% 20$ divulgaci\%C3\%B3n\%20de\%20\%C3\%A9sta.

República de Colombia. Corte Constitucional. (13 de septiembre de 1995). Ref.: Expediente No T-49272. [Sentencia T-411]. M.P. Alejandro Martínez Caballero. Disponible en https:// www.corteconstitucional.gov.co/relatoria/1995/t-411-95. htm 
República de Colombia. Corte Constitucional. (5 de junio de 1992). Ref.: Expediente T-778. [Sentencia T-406]. M.P. Ciro Angarita Baron. Disponible en https://www.corteconstitucional. gov.co/relatoria/1992/T-406-92.htm

República de Colombia. Presidencia de la República. (abril 15 de 2020). Por el cual se crea el impuesto solidario por el COVID 19, dentro del Estado de Emergencia Económica, Social y Ecológica dispuesto en el Decreto Legislativo 417 de 2020. [Decreto 568]. DO: 51286. Disponible en https:// www.funcionpublica.gov.co/eva/gestornormativo/norma. php?i=113664

República Federal de Alemania. (1949). Ley Fundamental de Bonn. [Ley Fundamental de la República de Alemania]. Disponible en https://www.gesetze-im-internet.de/gg/ BJNR000010949.html

Warren, S. \& Brandeis, L. (1890). The Rigth to Privacy. Harvard Law Review, 4(5), 193-220. https://doi.org/10.2307/1321160

* El presente artículo está enmarcado dentro del macroproyecto de investigación Derechos fundamentales y región caribe, un modelo de regionalización jurídica, en desarrollo por la Facultad de Derecho y Ciencias Políticas de la Corporación Universitaria del Caribe, CECAR. Adscrito al grupo de investigación GISCER.

Felix Ramon Mendoza de la Espriella es Doctor en Ciencias de la Educación de la Universidad Simón Bolívar (Colombia). Profesor Investigador Facultad de Derecho y Ciencias Políticas, de la Corporación Universitaria del Caribe-CECAR (Sincelejo, Colombia). https://orcid.org/0000-0001-7516-5158

Abraham Zamir Bechara Llanos es Doctor en Derecho de la Universidad Autónoma de Barcelona (España). Profesor Tiempo Completo Facultad de Derecho y Ciencias Políticas, de la Corporación Universitaria del Caribe-CECAR (Sincelejo, Colombia). https://orcid. org/0000-0002-6571-9804 
Joe Caballero Hernández es Magister en Derecho de la Universidad de Cartagena (Colombia). Profesor Tiempo Completo Facultad de Derecho y Ciencias Políticas, de la Corporación Universitaria del Caribe-CECAR (Sincelejo, Colombia). https://orcid.org/0000-0002-56575845 